\title{
Effizienz
}

\section{ist gefragt}

\section{Efficiency is in Demand}

Dear Reader,

Many companies in the agricultural sector have a critical view of the current situation. In particular, low producer prices, the uncertain political situation and social demands are negatively affecting the willingness of many farmers to invest. If new investment is nevertheless made, precise, efficient machines that conserve resources and protect the environment are especially in demand.

For that reason, the trend towards the further automation of processes linked with intelligent data management systems is continuing this year. This is also shown by the 311 submissions to the Agritechnica Innovations medal competition. I was particularly impressed, for example, by one Gold Medal winner: an innovative control system for internal tyre pressure from Agco Fendt. The system makes it possible to adjust the tyre pressure from 0.8 to $1.8 \mathrm{bar}$ within $30 \mathrm{~s}$, enabling farmers to switch quickly from field to road operation. Significant time savings are also possible with the ballasting system from John Deere, which won a Silver Medal. The device ensures perfect ballasting of the tractor from the driver's cab within just a few seconds. This and many other innovations for the tractor sector are presented in our cover story on page 14 .

Many of the new developments presented at Agritechnica from 10 to 14 November (preview days 8 and 9 November) are aimed at improving efficiency. Even if the current situation on the markets is tense, the numerous innovations are certain to attract large numbers of visitors to Hannover once again. I at least am looking forward to seeing the innovations at first hand and to have the opportunity to hold many interesting discussions.

See you in Hannover! 